\title{
Role of Nuclear Receptors in Exercise-Induced Muscle Adaptations
}

\author{
Barbara Kupr, Svenia Schnyder, and Christoph Handschin
}

Biozentrum, University of Basel, Basel 4056, Switzerland

Correspondence: christoph.handschin@unibas.ch

\begin{abstract}
Skeletal muscle is not only one of the largest, but also one of the most dynamic organs. For example, plasticity elicited by endurance or resistance exercise entails complex transcriptional programs that are still poorly understood. Various signaling pathways are engaged in the contracting muscle fiber and collectively culminate in the modulation of the activity of numerous transcription factors (TFs) and coregulators. Because exercise confers many benefits for the prevention and treatment of a wide variety of pathologies, pharmacological activation of signaling pathways and TFs is an attractive avenue to elicit therapeutic effects. Members of the nuclear receptor (NR) superfamily are of particular interest owing to the presence of welldefined DNA- and ligand-binding domains. In this review, we summarize the current understanding of the involvement of NRs in muscle biology and exercise adaptation.
\end{abstract}

Keletal muscle is the largest organ in our body, Saccounts for $\sim 40 \%$ of body mass, contains $\sim 50 \%-75 \%$ of all body proteins, and takes up $\sim 85 \%$ of glucose on insulin stimulation (Frontera and Ochala 2015). Moreover, even though skeletal muscle only contributes $\sim 30 \%$ to energy expenditure at rest, $90 \%$ of the 20 -fold peak increase in energy expenditure during physical activity can be attributed to muscle. Accordingly, skeletal muscle is one of the main sites of metabolism of glucose, fatty acids, ketone bodies, and lactate. The energy generated in this process is used for contraction and hence the generation of force, including that which is required to maintain posture and breathing. In addition, skeletal muscle function is instrumental to maintain body temperature, and is one of the main storage sites for glucose (in the form of glycogen), lipids (as neutral triglyceride lipid droplets), and amino acids. With the detection of myokines, muscle has also been defined as endocrine organ exerting auto-, para-, and endocrine effects (Schnyder and Handschin 2015). Finally, skeletal muscle can contribute to the detoxification of predominantly endogenous metabolites, such as L-kynurenine or excessive ketone bodies (Svensson et al. 2016).

To be able to cope with these diverse functions, skeletal muscle is one of the most dynamic tissues. On different stimuli, massive adaptations are initiated and, if the respective stimuli persist, maintained chronically. Most strikingly, biochemical, metabolic, and contractile properties are modulated by physical activity. Many different signaling pathways are activated during and after exercise bouts and collectively result in the regulation of a complex transcriptional program (Egan and Zierath 2013; Kupr and Hand-

Editors: Juleen R. Zierath, Michael J. Joyner, and John A. Hawley

Additional Perspectives on The Biology of Exercise available at www.perspectivesinmedicine.org

Copyright (C) 2017 Cold Spring Harbor Laboratory Press; all rights reserved; doi: 10.1101/cshperspect.a029835

Cite this article as Cold Spring Harb Perspect Med 2017;7:a029835 
B. Kupr et al.

schin 2015; Hoppeler 2016) that varies between endurance and resistance exercise resulting in distinct and specific outcomes (Hawley et al. 2014; Camera et al. 2016; Qaisar et al. 2016). Importantly, these two types of exercise not only improve muscle endurance and strength, respectively, but also confer beneficial effects for the prevention and treatment of many different pathologies (Handschin and Spiegelman 2008; Booth et al. 2012; Pedersen and Saltin 2015).

Even though the epidemiological association of a sedentary lifestyle with the increased risk for many chronic diseases is clear, and inversely, the benefits of exercise have been shown (Pedersen and Saltin 2015), the incidence of most of these pathologies is on the rise worldwide. Exercise interventions often fail because of lack of adherence and compliance. Moreover, subgroups of patients exist with exercise intolerance, defined either as the inability to train or as a detrimental outcome of physical activity. It is therefore intriguing to speculate that a better knowledge of the complex molecular mechanisms that underlie exercise adaptations in skeletal muscle could be leveraged to design so-called "exercise mimetics," pharmacological interventions that elicit exercise-like effects (Handschin 2016). Of the transcription factors
(TFs) that have been described in skeletal muscle plasticity, those belonging to the superfamily of nuclear receptors (NRs) are of particular interest in this regard. NRs are the largest family of TFs in metazoans (Escriva et al. 2004; Bookout et al. 2006). With few exceptions, all of the NRs are characterized by a highly conserved domain structure (Fig. 1A) (Germain et al. 2006). An amino-terminal A/B domain, often with an intrinsic transcriptional activation function (AF1), is followed by a DNA-binding domain C that entails a zinc finger-based DNA-binding domain. A hinge region $\mathrm{D}$ then links to the ligand-binding and dimerization domain $\mathrm{E} / \mathrm{F}$, of which helix 12 includes the activation function 2 (AF-2). The NR superfamily includes the classic steroid hormone receptors, "orphan" receptors with no known endogenous ligand, and "adopted" NRs for which endogenous ligands have been identified. All of the NRs with functional DNA-binding domains are recruited to either individual or direct, inverted or everted repeats of canonical nucleotide hexamer halfsites with variable spacing (Fig. 1B). Although most of the steroid hormone receptors bind as homodimers, other NRs can also be recruited to target sites as monomers or as heterodimers with the common binding partners retinoid $\mathrm{X}$ receptors $\alpha, \beta$, or $\gamma(\operatorname{RXR} \alpha / \beta / \gamma$, official no-

A

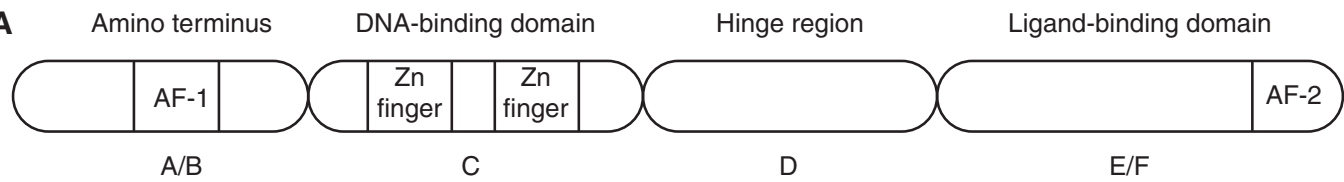

B Canonical NR hexamer half-site: $A G(G / T) T C A$
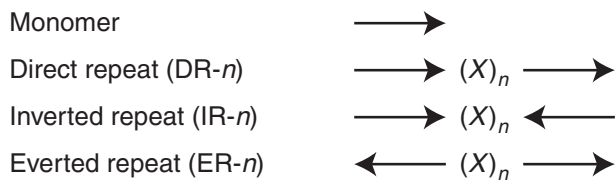

Figure 1. Structure and DNA-binding sites of nuclear receptors (NRs). (A) Schematic representation of the different NR domains. $(B)$ Arrangements of DNA-binding sites of NRs. $(X)_{n}$ indicates a spacer of $n$ arbitrary nucleotides $X$ between the hexamer half-sites. The repeats are accordingly designated as DR- $n$, IR- $n$, or ER- $n$, for example, DR-1 for a direct repeat with a spacer of one nucleotide. 
menclature NR2B1/2/3) (see Auwerx et al. 1999). Type I NRs reside in the cytoplasm and translocate into the nucleus on ligand binding and activation. Type II NRs are found in the nucleus, heterodimerize with RXRs, often sit on response elements and then exchange corepressors for coactivators when activated by ligands. Similarly, the type III and type IV NRs are retained in the nucleus and bind to DNA-response elements as homodimers to hexamer repeats (type III) or as monomers or dimers, but only to a single hexamer half site (type IV). NR ligands include hormones, lipids, steroids, retinoids, xenobiotics, and synthetic compounds. Accordingly, many NRs sense the energy or the dietary status of a cell and regulate metabolism and energy expenditure (Pardee et al. 2011). Not surprisingly, various NRs have thus also been implicated in the regulation of myogenesis, skeletal muscle function, and plasticity. In this review, these NRs and important cofactors are highlighted and their role in exercise-induced muscle adaptations as well as their potential as drug targets is discussed.

\section{THE NR SUPERFAMILY AND ITS ROLE IN EXERCISE-INDUCED SKELETAL MUSCLE ADAPTATION}

A surprisingly high proportion of NRs in mice, 35 out of 49 , shows detectable gene expression in skeletal muscle (Table 1) (Bookout et al. 2006). However, a potential role in skeletal muscle function and exercise adaptation has been studied for only a subset of those (Fig. 2). Current knowledge and recent updates about these NRs are summarized in the following paragraphs and in Table 2. (Further information and primary literature can be found in additional excellent review articles on this topic, for example, Smith and Muscat 2005; Fan et al. 2011, 2013; Fan and Evans 2015; Mizunoya 2015.)

\section{Subfamily 1, Group A: Thyroid Hormone Receptors-Type II}

Hypo- and hyperthyroidism have profound effects on whole body metabolism. The effect of thyroid hormone is mediated by two thyroid hormone receptors (TRs), TR $\alpha$ (NR1A1) and TR $\beta$ (NR1A2). In skeletal muscle, hypothyroidism promotes a shift toward slow, oxidative, while injection of thyroid hormone to fast, glycolytic muscle fibers, respectively (Smith and Muscat 2005; Mizunoya 2015). In loss-of-function studies, knockout of TR $\alpha$, but not of TR $\beta$, was likewise associated with an increase in oxidative muscle fibers (Yu et al. 2000). Interestingly, however, concomitant ablation of both TRs exacerbated the switch from type II to type I fibers, indicating that TR $\beta$ might boost the action of TR $\alpha$ in skeletal muscle. TR $\alpha$ is furthermore induced by contraction in skeletal muscle leading to a modulation of carbohydrate and lipid metabolism (Lima et al. 2009). At least some of the effects of low levels of thyroid hormone on tricarboxylic acid (TCA) cycle activity and mitochondrial oxidative phosphorylation (OXPHOS) in skeletal muscle could be meditated by activation of the peroxisome proliferatoractivated receptor $\gamma$ coactivator- $1 \alpha$ (PGC- $1 \alpha)$ (Irrcher et al. 2003), a master regulator of mitochondrial function and oxidative metabolism, potentially in a fiber type-specific manner (Bahi et al. 2005).

\section{Subfamily 1, Group C: Peroxisome Proliferator-Activated Receptors -Type II}

In mammals, three peroxisome proliferatoractivated receptors (PPARs) PPAR $\alpha$ (NR1C1), $\mathrm{PPAR} \beta / \delta$ (NR1C2), and PPAR $\gamma$ (NR1C3) have been identified, all of which are expressed in skeletal muscle and have been implicated in regulating lipid metabolism. The PPARs heterodimerize with RXRs and bind to PPAR-response elements consisting of a core of a direct repeat of two hexamer half sites with a spacing of 1 nucleotide (DR-1) in promoter and enhancer regions of their target genes.

PPAR $\alpha$, activated by free fatty acids and fibrate drugs, strongly controls fatty acid oxidation, TCA cycle activity, and mitochondrial OXPHOS. Interestingly, however, muscle lipid metabolism is only slightly altered in PPAR $\alpha$ knockout animals, implying a functional compensation by $\operatorname{PPAR} \beta / \delta$, which shares many common target genes with $\operatorname{PPAR} \alpha$ (Muoio 
Table 1. Human and mouse nuclear receptors

\begin{tabular}{|c|c|c|c|}
\hline NR subfamily and group & NR nomenclature & Trivial name & Muscle expression (Mus musculus) $^{\mathrm{a}}$ \\
\hline \multirow[t]{2}{*}{$\overline{1 \mathrm{~A}}$} & NR1A1 & $\mathrm{TR} \alpha$ & $\mathrm{H}$ \\
\hline & NR1A2 & TR $\beta$ & $\mathrm{L}$ \\
\hline \multirow[t]{3}{*}{$1 \mathrm{~B}$} & NR1B1 & $\operatorname{RAR} \alpha$ & $\mathrm{H}$ \\
\hline & NR1B2 & RAR $\beta$ & I \\
\hline & NR1B3 & RAR $\gamma$ & I \\
\hline \multirow[t]{3}{*}{$1 \mathrm{C}$} & NR1C1 & $\operatorname{PPAR} \alpha$ & I \\
\hline & NR1C2 & $\operatorname{PPAR} \beta / \delta$ & I \\
\hline & NR1C3 & $\operatorname{PPAR} \gamma$ & I \\
\hline \multirow[t]{2}{*}{$1 \mathrm{D}$} & NR1D1 & $\operatorname{REVERB} \alpha$ & $\mathrm{H}$ \\
\hline & NR1D2 & REVERB $\beta$ & I \\
\hline \multirow[t]{3}{*}{$1 \mathrm{~F}$} & NR1F1 & $\mathrm{ROR} \alpha$ & $\mathrm{H}$ \\
\hline & NR1F2 & ROR $\beta$ & $\mathrm{L}$ \\
\hline & NR1F3 & $\mathrm{ROR} \gamma$ & $\mathrm{H}$ \\
\hline \multirow[t]{4}{*}{$1 \mathrm{H}$} & $\mathrm{NR} 1 \mathrm{H} 2$ & LXR $\beta$ & I \\
\hline & NR1H3 & $\operatorname{LXR} \alpha$ & $\mathrm{H}$ \\
\hline & NR1H4 & $\mathrm{FXR} \alpha$ & nd \\
\hline & $\mathrm{NR} 1 \mathrm{H} 5^{\mathrm{b}}$ & FXR $\beta^{\mathrm{b}}$ & nd \\
\hline \multirow[t]{3}{*}{$1 \mathrm{I}$} & NR1I1 & VDR & $\mathrm{L}$ \\
\hline & NR1I2 & PXR & nd \\
\hline & NR1I3 & CAR & nd \\
\hline \multirow[t]{2}{*}{$2 \mathrm{~A}$} & NR2A1 & $\mathrm{HNF} 4 \alpha$ & nd \\
\hline & NR2A2 & $\mathrm{HNF} 4 \gamma$ & nd \\
\hline \multirow[t]{3}{*}{$2 \mathrm{~B}$} & NR2B1 & $\mathrm{RXR} \alpha$ & $\mathrm{H}$ \\
\hline & NR2B2 & $\mathrm{RXR} \beta$ & $\mathrm{H}$ \\
\hline & NR2B3 & $\mathrm{RXR} \gamma$ & $\mathrm{H}$ \\
\hline \multirow[t]{2}{*}{$2 \mathrm{C}$} & NR2C1 & TR2 & $\mathrm{L}$ \\
\hline & $\mathrm{NR} 2 \mathrm{C} 2$ & TR4 & I \\
\hline \multirow[t]{2}{*}{$2 \mathrm{E}$} & NR2E1 & TLX & nd \\
\hline & NR2E3 & PNR & nd \\
\hline \multirow[t]{3}{*}{$2 \mathrm{~F}$} & $\mathrm{NR} 2 \mathrm{~F} 1$ & COUP-TFI & $\mathrm{L}$ \\
\hline & $\mathrm{NR} 2 \mathrm{~F} 2$ & COUP-TFII & I \\
\hline & NR2F6 & EAR2 & $I^{\mathrm{c}}$ \\
\hline \multirow[t]{2}{*}{$3 \mathrm{~A}$} & NR3A1 & $\mathrm{ER} \alpha$ & I \\
\hline & NR3A2 & $\mathrm{ER} \beta$ & nd \\
\hline \multirow[t]{3}{*}{$3 \mathrm{~B}$} & NR3B1 & $\mathrm{ERR} \alpha$ & $\mathrm{H}$ \\
\hline & NR3B2 & ERR $\beta$ & I \\
\hline & NR3B3 & ERR $\gamma$ & I \\
\hline \multirow[t]{4}{*}{$3 \mathrm{C}$} & NR3C1 & GR & $\mathrm{H}$ \\
\hline & NR3C2 & MR & I \\
\hline & NR3C3 & PR & nd \\
\hline & NR3C4 & $\mathrm{AR}$ & $\mathrm{H}$ \\
\hline \multirow[t]{3}{*}{$4 \mathrm{~A}$} & NR4A1 & NUR77 & $\mathrm{H}$ \\
\hline & NR4A2 & NURR1 & I \\
\hline & NR4A3 & NOR1 & $\mathrm{H}$ \\
\hline \multirow[t]{2}{*}{$5 \mathrm{~A}$} & NR5A1 & SF1 & nd \\
\hline & NR5A2 & LRH1 & nd \\
\hline $6 \mathrm{~A}$ & NR6A1 & GCNF1 & $\mathrm{L}$ \\
\hline \multirow[t]{2}{*}{ OB } & NR0B1 & DAX1 & nd \\
\hline & NR0B2 & SHP & nd \\
\hline
\end{tabular}

NRs highlighted by gray shading are discussed in this review.

H, High expression; I, intermediate expression; L, low expression; nd, not detected.

${ }^{\mathrm{a}} \mathrm{NR}$ gene expression in mouse muscle according to Bookout et al. (2006).

${ }^{\mathrm{b}} \mathrm{FXR} \beta$ is a pseudogene in the human genome.

${ }^{c}$ The expression of NR2F6/Ear2 was not reported in to Bookout et al. (2006) and muscle expression confirmed using BioGPS and GeneCards. 
Nuclear Receptors in Exercise Adaptations

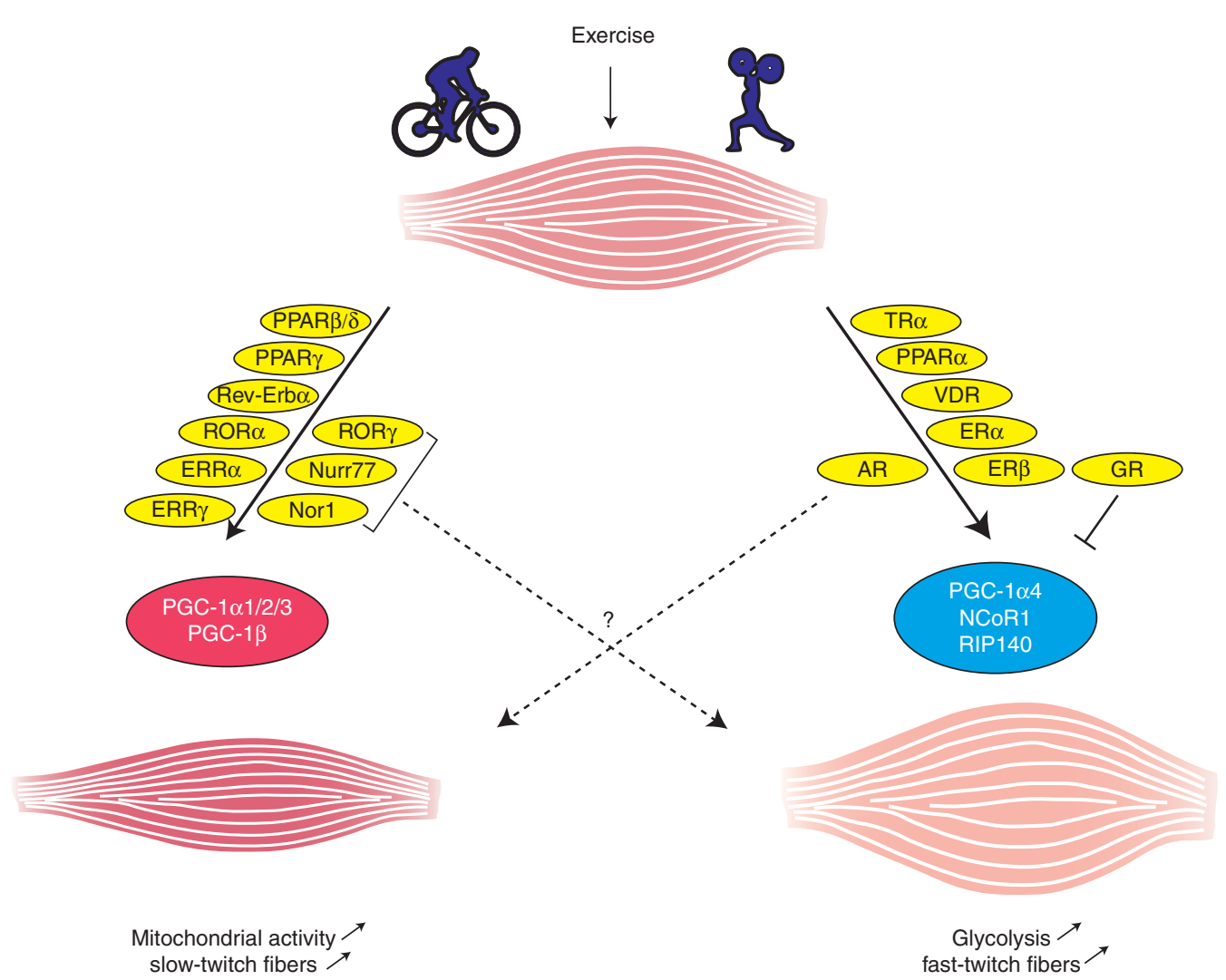

Figure 2. Regulation of endurance and resistance exercise adaptations in skeletal muscle by nuclear receptors (NRs) and coregulators. For some NRs, including ROR $\gamma$, Nur77, Nor1, or AR, a role in both the promotion of an oxidative and a glycolytic muscle phenotype has been proposed in different experimental models.

et al. 2002). Accordingly, muscle-specific overexpression of either of these PPARs results in elevated oxidative metabolism of fatty acids (Luquet et al. 2003; Finck et al. 2005). However, unexpectedly and diametrically opposite to $\operatorname{PPAR} \beta / \delta$, muscle-specific PPAR $\alpha$ transgenic mice are susceptible to the development of insulin resistance, have a reduced endurance capacity, and depict an oxidative to glycolytic fiber type switch (Gan et al. 2013). Inversely, more oxidative fibers are detected in muscle-specific PPAR $\alpha$ knockout animals (Gan et al. 2013). This negative cross talk between PPAR $\alpha$ and PPAR $\beta$ / $\delta$ is mediated by the miRNAs miR-208b and miR-499, which boost oxidative and repress glycolytic fiber determination (Gan et al. 2013).

The transcription of PPAR $\beta / \delta$ is induced by acute and chronic endurance exercise and sub- sequently promotes a glycolytic to oxidative fiber-type switch linked to higher OXPHOS activity, reduced fat mass, and improved glucose tolerance (Fan and Evans 2015). Muscle-specific overexpression of PPAR $\beta / \delta$ (Gan et al. 2011) or of PPAR $\beta / \delta$ fused to the strong VP16 transcriptional activation domain (Wang et al. 2004) accordingly enhances endurance exercise performance. Similarly, administration of the synthetic PPAR $\beta / \delta$ ligand GW501516 improves oxidative metabolism and enhances the effect of endurance exercise training (Narkar et al. 2008). In contrast, skeletal muscle-specific ablation of the PPAR $\beta / \delta$ gene results in a shift toward glycolytic fibers, reduced fatty acid catabolism and OXPHOS activity, decreased exercise performance, as well as exacerbated insulin resistance, glucose intolerance, 
B. Kupr et al.

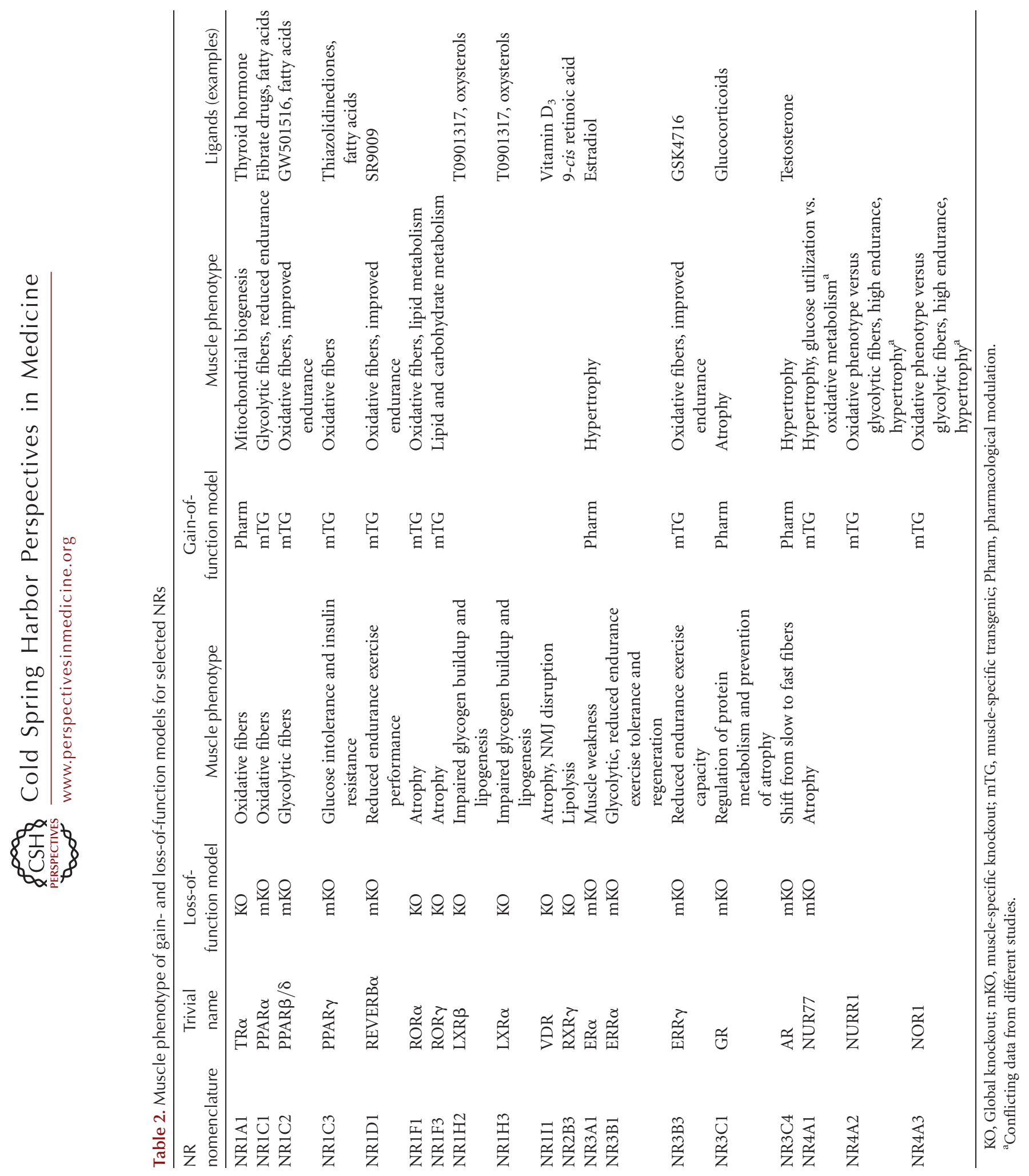


and obesity when fed a high-fat diet (Schuler et al. 2006). Interestingly, PPAR $\beta / \delta$ controls the expression of PGC- $1 \alpha$ and thereby enhances its own activity by boosting transcriptional coactivation (Schuler et al. 2006). Thus, as a downstream effector from PPAR $\beta / \delta$, PGC- $1 \alpha$ exerts potent effects on endurance exercise adaptations even in the absence of PPAR $\beta / \delta$ in skeletal muscle (Pérez-Schindler et al. 2014).

Of the three PPARs, PPAR $\gamma$ depicts the lowest expression in skeletal muscle. Nevertheless, a role in the control of muscle metabolism was implied by observations in muscle-specific PPAR $\gamma$ knockout mice that develop adiposity and at least a mild insulin resistance under high-fat diet (Hevener et al. 2003; Norris et al. 2003). Animals with a muscle-specific transgenic overexpression of a modified PPAR $\gamma$ (harboring a mutation in the inhibitory phosphorylation site Ser86 and a carboxy-terminal fusion to the CR1 region of the adenovirus Ela gene that strongly promotes transcriptional activity) are protected against diet-induced insulin resistance and glucose intolerance, secrete elevated levels of adiponectin from muscle, and show a switch toward more oxidative fibers, similar to PPAR $\beta / \delta$ (Amin et al. 2010).

\section{Subfamily 1, Group D: Rev-Erb-Type IV}

Rev-Erb $\alpha$ (NR1D1) and Rev-Erb $\beta$ (NR1D2) are NRs with a dual role regulating the circadian clock and cellular metabolism (Cho et al. 2012). On binding of heme, the endogenous ligand of these NRs (Yin et al. 2007), the RevErbs recruit corepressors such as the NR corepressor 1 (NCoR1) or the histone deacetylase 3 (HDAC3) and thus transcriptionally repress target genes. Gain- and loss-of-function studies of muscle Rev-Erb $\alpha$ revealed a prominent involvement in the regulation of mitochondrial biogenesis, mitophagy, promotion of a slow fiber type, and, ultimately, higher endurance capacity (Woldt et al. 2013). Mechanistically, muscle-specific ablation of the Rev-Erb $\alpha$ gene was associated with reduced activity of the AMPdependent protein kinase (AMPK)-sirtuin 1 (SIRT1)-PGC-1 $\alpha$ signaling axis (Woldt et al. 2013). Accordingly, mice treated with the Rev-
Erb $\alpha$ agonist SR9009 show increased activation of these factors (Woldt et al. 2013). A contribution of Rev-Erb $\beta$ to the control of lipid uptake has been postulated (Ramakrishnan et al. 2005). However, in contrast to the well-established role of Rev-Erb $\alpha$ in the control of oxidative muscle function, the function of Rev-Erb $\beta$ in skeletal muscle remains poorly understood.

\section{Subfamily 1, Group F: Retinoid-Related Orphan Receptors-Type IV}

The transcriptional activity of the retinoid-related orphan receptors (RORs) is negatively affected by the Rev-Erb receptors, at least in the control of the circadian clock. However, with regard to skeletal muscle function, $\operatorname{ROR} \alpha$ (NR1F1) elicits changes that are in part similar to those described for Rev-Erb $\alpha$, in particular in the regulation of lipid metabolism (Fitzsimmons et al. 2012). In addition, $\operatorname{ROR} \alpha$ also affects muscle lipogenesis, cholesterol efflux, insulin sensitivity, and glucose uptake. Mechanistically, these observations have been linked to a modulation of protein kinase B (PKB/Akt) and AMPK signaling coupled to a change in PGC- $1 \alpha$ gene expression (Fitzsimmons et al. 2012). ROR $\gamma$ (NR1F3) is also highly expressed in skeletal muscle, but the function is less clear. Overexpression studies in muscle have linked ROR $\gamma$ to the regulation of genes involved in lipid and carbohydrate metabolism, and possibly muscle mass through the induction of the myostatin gene (Raichur et al.2010). However, the physiological relevance of these observations is unknown. Moreover, because $\operatorname{ROR} \gamma$ induces $\operatorname{ROR} \alpha$ and Rev-Erb $\alpha$, it is not clear whether these effects are direct or indirect (Raichur et al. 2010).

\section{Subfamily 1, Group H: Liver X Receptor-Type II}

Liver X receptors (LXR) LXR $\alpha(\mathrm{NR} 1 \mathrm{H} 3)$ and LXR $\beta$ (NR1H2) have potent effects on cholesterol efflux in various tissues and cell types. Both receptors have been linked to anabolic pathways in skeletal muscle, including glycogen buildup and lipogenesis (Archer et al. 2014). Long-term treatment of mice with the synthetic 
B. Kupr et al.

LXR agonist T0901317 elevated lipogenesis and reverse cholesterol transport in wild-type and in $\operatorname{LXR} \alpha$, but to a lesser extent in LXR $\beta$ knockout animals, indicating that LXR $\beta$ might constitute the more relevant LXR variant in skeletal muscle (Hessvik et al. 2010). The anabolic function of the LXRs indicate that these receptors are involved in regeneration processes between exercise bouts to replenish intramuscular glycogen and lipid stores, for example, when coactivated by PGC-1 $\alpha$ (Summermatter et al. 2010).

\section{Subfamily 1, Group I: Vitamin D Receptor-Type II}

The vitamin D receptor (VDR, NR1I1) is involved in regulating mineral metabolism. In humans, polymorphisms of the VDR gene are associated with aberrations in muscle strength (Pojednic and Ceglia 2014). In mice, VDR gene ablation results in muscle fiber atrophy, motor deficits, decreased locomotive activity after exercise and reduced neuromuscular maintenance (Girgis et al. 2014; Sakai et al. 2015). Endogenous VDR gene expression is induced after resistance training in rats (Makanae et al. 2015). Combined with studies using vitamin D administration in human patients, a positive role of the VDR in the control of muscle mass, fiber hypertrophy, and anabolic capacity can be predicted (Pojednic and Ceglia 2014).

\section{Subfamily 2, Group B: Retinoid X Receptors-Type III}

In addition to their ability to homodimerize, the retinoid $\mathrm{X}$ receptor (RXR) family members $\mathrm{RXR} \alpha(\mathrm{NR} 2 \mathrm{~B} 1), \mathrm{RXR} \beta$ (NR2B2), and RXR $\gamma$ (NR2B3) are obligate heterodimerization partners for a number of NRs and thus play a unique role in modulating and integrating the function of these different receptors (Perez et al. 2012; Evans and Mangelsdorf 2014). Although RXR $\beta$ is ubiquitously expressed, $\operatorname{RXR} \alpha$ and $\operatorname{RXR} \gamma$ levels are enriched in some tissues, including skeletal muscle. Global RXR $\gamma$ knockout animals have a leaner phenotype after a high-fat diet feeding, which is most likely attributed to an up-regulation of lipoprotein lipase in skeletal muscle (Haugen et al. 2004). However, little is known about the specific functions of all three RXRs in skeletal muscle. Intriguingly, NR/RXR heterodimers are classified as "permissive" and "nonpermissive.” Permissive RXR heterodimers include the interactions with PPARs or LXRs and thus are activated by either RXR or PPAR/LXR ligands. In contrast, TR and VDR interact with RXR in a nonpermissive manner and therefore are not activated by 9-cis retinoic acid or other RXR ligands (Perez et al. 2012). Activation of RXRs in skeletal muscle would thus be expected to be linked to increased action of permissive but not of nonpermissive NR heterodimerization partners.

\section{Subfamily 3, Groups A and C: Estrogen Receptor, Androgen Receptor, Glucocorticoid Receptor-Type I}

Estrogens have primarily been linked to reduced inflammation and enhanced regeneration of skeletal muscle in ovariectomized rodents or postmenopausal women (Lowe et al. 2010; Diel 2014). In addition, it is now clear that estrogens also improve muscle mass and strength even though it is disputed whether increased quantity or quality of muscle is the driver of these changes. Both estrogen receptors (ERs) $\mathrm{ER} \alpha(\mathrm{NR} 3 \mathrm{~A} 1)$ and $\mathrm{ER} \beta(\mathrm{NR} 3 \mathrm{~A} 2)$ are expressed in skeletal muscle, are induced by exercise (Wiik et al. 2005) and thought to contribute to the effects of estrogen in this tissue. Intriguingly, at least some of the effects of estrogen, for example, activation of AMPK, might be mediated by nongenomic signaling pathways and thereby reinforce the receptor-dependent adaptations (Oosthuyse and Bosch 2012).

Male sex hormones elicit potent anabolic effects on skeletal muscle tissue, but also enhance muscle regeneration (O'Connell and $\mathrm{Wu}$ 2014). Most of these effects are mediated by activation of the androgen receptor (AR) NR3C4, in particular, the strong boost in muscle protein synthesis. Accordingly, muscle hypertrophy elicited by resistance training is attenuated by AR blockage (Inoue et al. 1994). Regulation of AR levels after resistance exercise seems to depend on a complex control of contractile and 
nutritional cues, and can vary between different fiber types (Gonzalez et al. 2016). Similarly, the contradicting results of physiological testosterone fluctuations and muscle hypertrophy in different human studies imply a more complex interaction between androgens, growth hormone, and insulin-like growth factor 1 (IGF1) in this context (Gonzalez et al. 2016). However, the anabolic effect of superphysiological concentrations of testosterone consistently includes an improvement of muscle mass caused by hypertrophy of type I and type II fibers as well as muscle strength and power, whereas fatigability and muscle quality, defined as ratio between muscle strength to size, are less affected in humans (O'Connell and Wu 2014). The central role for the AR to regulate muscle development, mass, strength, and fatigue resistance was confirmed by experiments in male AR knockout mice (MacLean et al. 2008). Somewhat contradictory, a different AR knockout mouse model depicted a shift from oxidative toward glycolytic muscle fibers, thereby also linking the AR to the maintenance of slow-twitch oxidative fibers (Altuwaijri et al. 2004).

In contrast to the positive effects of ERs and the AR on muscle mass and function, the glucocorticoid receptor (GR), NR3C1, has been associated with atrophy of primarily type II muscle fibers (Kuo et al. 2013; Schakman et al. 2013). Cortisol, the ligand of the GR, is a stress hormone released during exercise, starvation, or sepsis that contributes to the metabolic remodeling in various tissues (Kraemer and Ratamess 2005). In skeletal muscle, one effect of cortisol is the stimulation of protein breakdown and the inhibition of protein synthesis (Schakman et al. 2013). Although short-term elevation of cortisol is a normal response to acute exercise bouts, chronic elevation can be an indicator of overtraining or training-induced stress. The ratio between testosterone and cortisol has been proposed to correlate with the anabolic and catabolic state of skeletal muscle, respectively, even though this interpretation is debated (Kraemer and Ratamess 2005). The GR is up-regulated by physical activity, most notably by eccentric resistance exercise bouts, but this induction is attenuated by chronic training, as is the increase in circulating cortisol. In line, a reduction in muscle mass is a common side effect in patients treated with corticosteroids. However, paradoxically, Duchenne muscular dystrophy patients profit from administration of glucocorticoids. Even though the mechanisms behind this therapeutic effect is unclear, anti-inflammatory properties, up-regulation of utrophin, normalization of intramyocellular calcium homeostasis, and stabilization of the muscle fiber membrane have been proposed to contribute to the positive outcome of glucocorticoid treatment in Duchenne patients (Matthews et al. 2016).

\section{Subfamily 3, Group B: Estrogen-Related Receptors-Type IV}

Estrogen-related receptors (ERRs) ERR $\alpha$ (NR3B1), ERR $\beta$ (NR3B2), and ERR $\gamma$ (NR3B3) are all substantially expressed in tissues with a high energetic demand, for example, skeletal muscle (Fan and Evans 2015). Muscle-specific $\mathrm{ERR} \alpha$ knockout animals show an impaired muscle regeneration capacity, compromised antioxidant response, reduced oxidative capacity, and angiogenesis (LaBarge et al. 2014). Moreover, these mice have a blunted response to highfat diet and exercise, including impaired exercise tolerance, and muscle fitness (LaBarge et al. 2014; Perry et al. 2014; Huss et al. 2015). ERR $\alpha$ gene expression is induced by physical activity in animals and humans, and this receptor then coordinates the expression of genes involved in lipid uptake, metabolism, and mitochondrial OXPHOS (Huss et al. 2015). Even though cholesterol has been recently postulated as endogenous ERR $\alpha$ ligand (Wei et al. 2016), the transcriptional activity of all three ERRs is thought to be mainly driven by coregulator binding. In the case of ERR $\alpha$, the coactivator PGC- $1 \alpha$ seems of particular relevance for the regulation of target genes in skeletal muscle (Mootha et al. 2004). In fact, the genomic context of regulatory elements in target gene enhancers and promoters might dynamically determine the interaction and activity of these two proteins (Salatino et al. 2016).

$\mathrm{ERR} \alpha$ and ERR $\gamma$ have a considerable overlap in binding sites and accordingly regulate similar metabolic genes (Fan and Evans 2015). 
B. Kupr et al.

Nevertheless, differences in the regulation of the TCA cycle and the inability of $\operatorname{ERR} \alpha$ to compensate for the loss of ERR $\gamma$ in null mice highlight the specific roles for these two receptors (Eichner and Giguere 2011). Like ERR $\alpha, E R R \gamma$ is induced by exercise. Skeletal muscle-specific overexpression of ERR $\gamma$ alone or when fused to VP16 leads to a switch to oxidative fiber types and induces mitochondrial biogenesis and angiogenesis, collectively resulting in an improved endurance capacity (Rangwala et al. 2010; Narkar et al. 2011). Many of these effects can also be elicited by treatment with the ERR $\gamma$-specific synthetic activator GSK4716 (Rangwala et al. 2010). Inversely, a reduced exercise capacity was observed in ERR $\gamma$ muscle-specific knockouts (Gan et al. 2013).

ERR $\beta$ is the least characterized receptor of this group and, despite high expression in skeletal muscle, regulation and function are largely unexplored. A partial redundancy between ERR $\beta$ and ERR $\gamma$ with regard to the maintenance of type I fibers in mixed muscle beds has been proposed (Gan et al. 2013), but mechanistic aspects and comprehensive analysis remain elusive.

\section{Subfamily 4, Group A: Neuron-Derived Clone $77 /$ Nerve Growth Factor IB, Neuron-Derived Orphan Receptor 1-Type IV}

All three mammalian members of this group of NRs, neuron-derived Clone $77 /$ nerve growth factor IB (Nur77) NR4A1, NR related 1 protein (Nurr1) NR4A2, and neuron-derived orphan receptor 1 (Nor1) NR4A3 are induced by a single bout of exhaustive endurance exercise in human skeletal muscle (Mahoney et al. 2005); however, little is known about the role of Nurr1 in this tissue. Nur77 is predominantly expressed in glycolytic muscle fibers and was first postulated to be involved in the control of glucose metabolism (Chao et al. 2007). Later findings surprisingly implied an involvement of Nur77 in the regulation of oxidative metabolism and, accordingly, muscle-specific overexpression of Nur77 results in an increase in the proportion of oxidative muscle fibers, and mitochondrial DNA content with a concomitant shift from glucose utilization to fatty acid oxidation and improved fatigue resistance (Chao et al. 2012). Recently, however, Nur77 activity was associated with muscle growth, most likely controlled by activation of the IGF1-Akt-mammalian target of rapamycin (mTOR) signaling axis leading to the up-regulation of a hypertrophic gene program and an attenuation of the expression of the proatrophic myostatin as well as the E3 ubiquitin ligases MAFbx and MuRF1 (Tontonoz et al. 2015). However, while skeletal muscle-specific Nur77 mice do not depict increased muscle mass despite fiber hypertrophy, animals with a specific gene ablation of Nur77 in skeletal muscle show reduced myofiber size and muscle mass (Tontonoz et al. 2015).

Like Nur77, Nor1 is also induced by acute exercise and $\beta 2$-adrenergic signaling however, both in glycolytic and oxidative muscle fibers (Fan et al. 2013). Skeletal muscle-specific overexpression of Nor 1 in mice results in an oxidative, high-endurance phenotype with increased mitochondrial number and DNA, elevated myoglobin, enhanced ATP production, and PGC-1 $\alpha$ gene expression (Pearen et al. 2013). Intriguingly, a shift from type I and IIb toward type IIa and IIx muscle fibers is observed in these animals (Mizunoya 2015). These fatigueresistant Nor1 transgenic animals also show improved autophagy after endurance exercise, leading to better clearing of debris in the tissue (Goode et al. 2016). Unexpectedly, Nor1 overexpression was recently also linked to muscle hypertrophy and increased vascularization in skeletal muscle via activation of the mTOR signaling pathway (Goode et al. 2016).

\section{NR COREGULATORS}

The transcriptional activity of NRs is affected by recruitment of coactivator and corepressor proteins, which can occur in a ligand-dependent and ligand-independent manner. In skeletal muscle, several coregulators have been identified that modulate metabolic and contractile properties at least in part by binding to the NRs described in this review. Most prominently, muscle-specific overexpression of PGC- $1 \alpha$ and the related PGC-1 $\beta$ are sufficient to promote a 
fiber-type switch toward type I/IIa and IIx, respectively, even though it is not clear whether the latter occurs under physiological conditions (Eisele and Handschin 2014). Of these two coactivators, only PGC- $1 \alpha$ levels and activity are clearly associated with physical activity (Lin et al. 2002; Kupr and Handschin 2015), and gain- and loss-of-function in skeletal muscle result in improved and impaired endurance capacity, respectively (Lin et al. 2002; Handschin et al. 2007). Recently, the PGC- $1 \alpha 4$ isoform was identified to promote a hypertrophic response in skeletal muscle (Ruas et al. 2012) in contrast to the PGC- $1 \alpha 1,-1 \alpha 2$, and $-1 \alpha 3$ isoforms that have been linked to an endurance program (Martinez-Redondo et al. 2015). The expression of the corepressor NCoR1 is higher in inactive skeletal muscle, and NCoR1 competes with PGC- $1 \alpha$ for binding to ERR $\alpha$ (Pérez-Schindler et al. 2012). Accordingly, muscle-specific NCoR1 knockout mice recapitulate many of the metabolic adaptations that are also observed in PGC$1 \alpha$ transgenic animals (Pérez-Schindler et al. 2012). Similarly, overexpression and knockout of the corepressor receptor-interacting protein 140 (RIP140) results in decreased and elevated numbers of oxidative muscle fibers, respectively (Seth et al. 2007). This complex still poorly understood regulatory network of coactivator and corepressor proteins is thus intricately linked to NR action in skeletal muscle plasticity (Schnyder et al. 2016).

\section{EXERCISE MIMETICS}

Several pharmacological agents have already been proposed to act as "exercise mimetics," including three that activate NRs: SR9009 (RevErb $\alpha)$, GSK4716 (ERR $\gamma$ ), and GW501516 $(\operatorname{PPAR} \beta / \delta)$ (Handschin 2016). With well-defined and conserved ligand-binding domains, it is conceivable that other NRs could also be targeted to take advantage of their function in skeletal muscle. Importantly, however, for none of the currently proposed "exercise mimetics," have efficacy and safety been tested in humans to date. The alarming use of some of these compounds as performance-enhancing drugs in athletes with a subsequent ban by the World
Anti-Doping Agency underlines the need for a better understanding of the mechanisms, side effects, toxicity, and dosage (Wall et al. 2016). The summary of NRs and coregulators in this review should further illustrate the regulatory complexity of skeletal muscle plasticity, which is vastly expanded by non-NR TFs and signaling pathways (Hoppeler 2016). Despite the results in animal models with a higher endurance capacity, the expected effects of pharmacological modulation of one NR in skeletal muscle are difficult to reconcile with the myriad of muscular and nonmuscular adaptations elicited by bona fide physical activity (Booth and Laye 2009).

\section{OPEN QUESTIONS}

Of the 35 NRs expressed in mouse skeletal muscle, we have discussed here 26 with a potential role in exercise adaptation and skeletal muscle plasticity. A majority of these promote an oxidative, high-endurance phenotype (Fig. 2). The signaling networks and transcriptional hierarchies between these receptors are, however, not clear. Moreover, it is unknown whether the high number of NRs with seemingly overlapping function is a sign of transcriptional redundancy or represents specific regulation of highly specialized adaptations. An oxidative phenotype can, for example, be achieved by a down-regulation of type I and IIb fibers in the case of Nor 1 or by the more classic shift from type IIb and IIx toward IIa and I as seen in overexpression studies with PPAR $\beta / \delta$ or ERR $\gamma$. Furthermore, the alternating classification of Nur77 and Nor1 as prooxidative and proglycolytic NRs highlight a potential discrepancy between the results obtained in different experimental contexts, for example, cultured muscle cells compared with the constitutive transgenic elevation in skeletal muscle in vivo. These somewhat contradictory results with regard to the effects on glucose and lipid oxidation as well as glycolytic and oxidative fiber promotion, respectively, will therefore have to be clarified in future studies. Furthermore, whether the effects of Nur77 and Nor1 on muscle mass are primarily mediated by altered myogenesis or represent a bona fide modulation of atrophy and hypertrophy in regeneration and exercise in 
B. Kupr et al.

adult muscle remains to be shown. Similarly, the extensive study of anabolic steroids emerged with a consensus of increased muscle hypertrophy in humans. Nevertheless, results obtained in some but not all AR knockout mouse models imply a role for the AR in promoting an oxidative, high-endurance phenotype. Similarly, the effect of genetic ablation of the TRs on fiber-type distribution might appear contradictory vis-àvis the mitochondrial boost elicited by shortterm treatment with thyroid hormone. These and other examples show that the choice of model and the way of treatment might significantly alter the outcome. Therefore, caution should be used for the extrapolation of results from cell culture, nonconditional knockouts, and transgenic animals to the physiological role of NRs in skeletal muscle in humans.

\section{CONCLUDING REMARKS}

Endurance and resistance exercise confer many beneficial health effects, which substantially lower the risk for many chronic diseases and are a therapeutic pillar for a number of different pathologies. Even though the molecular mechanisms of muscle plasticity are still poorly understood, NRs are attractive drug targets to take advantage of some of the therapeutic effects of exercise. The ever-increasing prevalence of chronic diseases, age-related afflictions and pathologies associated with exercise intolerance indicate that even partial "exercise mimetics" might confer a significant relief for patients and overburdened health care systems. However, at the moment, it is not clear whether such drugs exist and, if so, whether they can be effectively and safely used in patients. Therefore, physical activity and diet should stay at the forefront of disease prevention and treatment wherever possible (Booth et al. 2012; Pedersen and Saltin 2015) until better pharmacological interventions targeted at improving muscle function are available.

\section{ACKNOWLEDGMENTS}

We apologize for omission of a copious amount of primary literature because of space limita- tions. We thank Regula Furrer for critical comments on our manuscript. Work in our group is supported by the Swiss National Science Foundation, the European Research Council (ERC) Consolidator Grant 616830-MUSCLE_NET, Swiss Cancer Research Grant KFS-3733-082015, the Swiss Society for Research on Muscle Diseases (SSEM), SystemsX.ch, the Novartis Stiftung für Medizinisch-Biologische Forschung and the University of Basel. B.K. is the recipient of a Fellowship for Excellence of the International $\mathrm{PhD}$ Program of the Biozentrum, University of Basel.

The authors declare no conflict of interest.

\section{REFERENCES}

Altuwaijri S, Lee DK, Chuang KH, Ting HJ, Yang Z, Xu Q, Tsai MY, Yeh S, Hanchett LA, Chang HC, et al. 2004. Androgen receptor regulates expression of skeletal muscle-specific proteins and muscle cell types. Endocrine 25: 27-32.

Amin RH, Mathews ST, Camp HS, Ding L, Leff T. 2010. Selective activation of PPAR $\gamma$ in skeletal muscle induces endogenous production of adiponectin and protects mice from diet-induced insulin resistance. Am J Physiol Endorinol Metab 298: E28-E37.

Archer A, Laurencikiene J, Ahmed O, Steffensen KR, Parini P, Gustafsson JA, Korach-Andre M. 2014. Skeletal muscle as a target of LXR agonist after long-term treatment: Focus on lipid homeostasis. Am J Physiol Endocrinol Metab 306: E494-E502.

Auwerx J, Baulieu E, Beato M, Becker-Andre M, Burbach PH, Camerino G, Chambon P, Cooney A, Dejean A, Dreyer C, et al. 1999. A unified nomenclature system for the nuclear receptor superfamily. Cell 97: 161-163.

Bahi L, Garnier A, Fortin D, Serrurier B, Veksler V, Bigard AX, Ventura-Clapier R. 2005. Differential effects of thyroid hormones on energy metabolism of rat slow- and fast-twitch muscles. J Cell Physiol 203: 589-598.

Bookout AL, Jeong Y, Downes M, Yu RT, Evans RM, Mangelsdorf DJ. 2006. Anatomical profiling of nuclear receptor expression reveals a hierarchical transcriptional network. Cell 126: 789-799.

Booth FW, Laye MJ. 2009. Lack of adequate appreciation of physical exercise's complexities can pre-empt appropriate design and interpretation in scientific discovery. J Physiol 587: $5527-5539$.

Booth FW, Roberts CK, Laye MJ. 2012. Lack of exercise is a major cause of chronic diseases. Compr Physiol 2: 11431211.

Camera DM, Smiles WJ, Hawley JA. 2016. Exercise-induced skeletal muscle signaling pathways and human athletic performance. Free Radic Biol Med 98: 131-143.

Chao LC, Zhang Z, Pei L, Saito T, Tontonoz P, Pilch PF. 2007. Nur77 coordinately regulates expression of genes linked 
to glucose metabolism in skeletal muscle. Mol Endocrinol 21: $2152-2163$.

Chao LC, Wroblewski K, Ilkayeva OR, Stevens RD, Bain J, Meyer GA, Schenk S, Martinez L, Vergnes L, Narkar VA, et al. 2012. Skeletal muscle Nur77 expression enhances oxidative metabolism and substrate utilization. J Lipid Res 53: 2610-2619.

Cho H, Zhao X, Hatori M, Yu RT, Barish GD, Lam MT, Chong LW, DiTacchio L, Atkins AR, Glass CK, et al. 2012. Regulation of circadian behaviour and metabolism by REV-ERB- $\alpha$ and REV-ERB- $\beta$. Nature 485: $123-127$.

Diel P. 2014. The role of the estrogen receptor in skeletal muscle mass homeostasis and regeneration. Acta Physiol (Oxf) 212: 14-16.

Egan B, Zierath JR. 2013. Exercise metabolism and the molecular regulation of skeletal muscle adaptation. Cell Metab 17: 162-184.

Eichner LJ, Giguere V. 2011. Estrogen related receptors (ERRs): A new dawn in transcriptional control of mitochondrial gene networks. Mitochondrion 11: 544-552.

Eisele PS, Handschin C. 2014. Functional crosstalk of PGC-1 coactivators and inflammation in skeletal muscle pathophysiology. Semin Immunopathol 36: 27-53.

Escriva H, Bertrand S, Laudet V. 2004. The evolution of the nuclear receptor superfamily. Essays Biochem 40: 11-26.

Evans RM, Mangelsdorf DJ. 2014. Nuclear receptors, RXR, and the big bang. Cell 157: 255-266.

Fan W, Evans R. 2015. PPARs and ERRs: Molecular mediators of mitochondrial metabolism. Curr Opin Cell Biol 33: $49-54$.

Fan W, Downes M, Atkins A, Yu R, Evans RM. 2011. Nuclear receptors and AMPK: Resetting metabolism. Cold Spring Harb Symp Quant Biol 76: 17-22.

Fan W, Atkins AR, Yu RT, Downes M, Evans RM. 2013. Road to exercise mimetics: Targeting nuclear receptors in skeletal muscle. J Mol Endocrinol 51: T87-T100.

Finck BN, Bernal-Mizrachi C, Han DH, Coleman T, Sambandam N, LaRiviere LL, Holloszy JO, Semenkovich CF Kelly DP. 2005. A potential link between muscle peroxisome proliferator-activated receptor- $\alpha$ signaling and obesity-related diabetes. Cell Metab 1: 133-144.

Fitzsimmons RL, Lau P, Muscat GE. 2012. Retinoid-related orphan receptor $\alpha$ and the regulation of lipid homeostasis. J Steroid Biochem Mol Biol 130: 159-168.

Frontera WR, Ochala J. 2015. Skeletal muscle: A brief review of structure and function. Calcif Tissue Int 96: 183-195.

Gan Z, Burkart-Hartman EM, Han DH, Finck B, Leone TC, Smith EY, Ayala JE, Holloszy J, Kelly DP. 2011. The nuclear receptor PPAR $\beta / \delta$ programs muscle glucose metabolism in cooperation with AMPK and MEF2. Genes Dev 25: 2619-2630.

Gan Z, Rumsey J, Hazen BC, Lai L, Leone TC, Vega RB, Xie H, Conley KE, Auwerx J, Smith SR, et al. 2013. Nuclear receptor/microRNA circuitry links muscle fiber type to energy metabolism. J Clin Invest 123: 2564-2575.

Germain P, Staels B, Dacquet C, Spedding M, Laudet V. 2006. Overview of nomenclature of nuclear receptors. Pharmacol Rev 58: 685-704.

Girgis CM, Mokbel N, Cha KM, Houweling PJ, Abboud M, Fraser DR, Mason RS, Clifton-Bligh RJ, Gunton JE. 2014 The vitamin D receptor (VDR) is expressed in skeletal muscle of male mice and modulates 25-hydroxyvitamin D (25OHD) uptake in myofibers. Endocrinology 155: 3227-3237.

Gonzalez AM, Hoffman JR, Stout JR, Fukuda DH, Willoughby DS. 2016. Intramuscular anabolic signaling and endocrine response following resistance exercise: Implications for muscle hypertrophy. Sports Med 46: 671685.

Goode JM, Pearen MA, Tuong ZK, Wang SC, Oh TG, Shao EX, Muscat GE. 2016. The nuclear receptor, Nor-1, induces the physiological responses associated with exercise. Mol Endocrinol 30: 660-676.

Handschin C. 2016. Caloric restriction and exercise "mimetics": Ready for prime time? Pharmacol Res 103: $158-166$.

Handschin C, Spiegelman BM. 2008. The role of exercise and PGC1 $\alpha$ in inflammation and chronic disease. Nature 454: 463-469.

Handschin C, Chin S, Li P, Liu F, Maratos-Flier E, Lebrasseur NK, Yan Z, Spiegelman BM. 2007. Skeletal muscle fibertype switching, exercise intolerance, and myopathy in PGC-1 $\alpha$ muscle-specific knock-out animals. J Biol Chem 282: 30014-30021.

Haugen BR, Jensen DR, Sharma V, Pulawa LK, Hays WR, Krezel W, Chambon P, Eckel RH. 2004. Retinoid X receptor $\gamma$-deficient mice have increased skeletal muscle lipoprotein lipase activity and less weight gain when fed a high-fat diet. Endocrinology 145: 3679-3685.

Hawley JA, Hargreaves M, Joyner MJ, Zierath JR. 2014. Integrative biology of exercise. Cell 159: 738-749.

Hessvik NP, Boekschoten MV, Baltzersen MA, Kersten S, Xu X, Andersen H, Rustan AC, Thoresen GH. 2010. LXR $\beta$ is the dominant LXR subtype in skeletal muscle regulating lipogenesis and cholesterol efflux. Am J Physiol Endocrinol Metab 298: E602-E613.

Hevener AL, He WM, Barak Y, Le J, Bandyopadhyay G, Olson P, Wilkes J, Evans RM, Olefsky J. 2003. Musclespecific Pparg deletion causes insulin resistance. Nat Med 9: $1491-1497$.

Hoppeler H. 2016. Molecular networks in skeletal muscle plasticity. J Exp Biol 219: 205-213.

Huss JM, Garbacz WG, Xie W. 2015. Constitutive activities of estrogen-related receptors: Transcriptional regulation of metabolism by the ERR pathways in health and disease. Biochim Biophys Acta 1852: 1912-1927.

Inoue K, Yamasaki S, Fushiki T, Okada Y, Sugimoto E. 1994. Androgen receptor antagonist suppresses exercise-induced hypertrophy of skeletal muscle. Eur J Appl Physiol Occup Physiol 69: 88-91.

Irrcher I, Adhihetty PJ, Sheehan T, Joseph AM, Hood DA. 2003. PPAR $\gamma$ coactivator- $1 \alpha$ expression during thyroid hormone- and contractile activity-induced mitochondrial adaptations. Am J Physiol Cell Physiol 284: C1669C1677.

Kraemer WJ, Ratamess NA. 2005. Hormonal responses and adaptations to resistance exercise and training. Sports Med 35: 339-361.

Kuo T, Harris CA, Wang JC. 2013. Metabolic functions of glucocorticoid receptor in skeletal muscle. Mol Cell Endocrinol 380: 79-88. 
B. Kupr et al.

Kupr B, Handschin C. 2015. Complex coordination of cell plasticity by a PGC- $1 \alpha$-controlled transcriptional network in skeletal muscle. Front Physiol 6: 325.

LaBarge S, McDonald M, Smith-Powell L, Auwerx J, Huss JM. 2014. Estrogen-related receptor- $\alpha(E R R \alpha)$ deficiency in skeletal muscle impairs regeneration in response to injury. FASEB J 28: 1082-1097.

Lima GA, Anhe GF, Giannocco G, Nunes MT, Correa-Giannella ML, Machado UF. 2009. Contractile activity per se induces transcriptional activation of SLC2A4 gene in soleus muscle: Involvement of MEF2D, HIF-1a, and TRo transcriptional factors. Am J Physiol Endocrinol Metab 296: E132-E138.

Lin J, Wu H, Tarr PT, Zhang CY, Wu Z, Boss O, Michael LF, Puigserver P, Isotani E, Olson EN, et al. 2002. Transcriptional co-activator PGC- $1 \alpha$ drives the formation of slowtwitch muscle fibres. Nature 418: 797-801.

Lowe DA, Baltgalvis KA, Greising SM. 2010. Mechanisms behind estrogen's beneficial effect on muscle strength in females. Exerc Sport Sci Rev 38: 61-67.

Luquet S, Lopez-Soriano J, Holst D, Fredenrich A, Melki J, Rassoulzadegan M, Grimaldi PA. 2003. Peroxisome proliferator-activated receptor $\delta$ controls muscle development and oxidative capability. FASEB J 17: 2299-2301.

MacLean HE, Chiu WS, Notini AJ, Axell AM, Davey RA, McManus JF, Ma C, Plant DR, Lynch GS, Zajac JD. 2008. Impaired skeletal muscle development and function in male, but not female, genomic androgen receptor knockout mice. FASEB J 22: 2676-2689.

Mahoney DJ, Parise G, Melov S, Safdar A, Tarnopolsky MA. 2005. Analysis of global mRNA expression in human skeletal muscle during recovery from endurance exercise. FASEB J 19: 1498-1500.

Makanae Y, Ogasawara R, Sato K, Takamura Y, Matsutani K, Kido K, Shiozawa N, Nakazato K, Fujita S. 2015. Acute bout of resistance exercise increases vitamin $\mathrm{D}$ receptor protein expression in rat skeletal muscle. Exp Physiol 100: $1168-1176$.

Martinez-Redondo V, Pettersson AT, Ruas JL. 2015. The hitchhiker's guide to PGC- $1 \alpha$ isoform structure and biological functions. Diabetologia 58: 1969-1977.

Matthews E, Brassington R, Kuntzer T, Jichi F, Manzur AY. 2016. Corticosteroids for the treatment of Duchenne muscular dystrophy. Cochrane Database Syst Rev 5: CD003725.

Mizunoya W. 2015. Nuclear receptors and skeletal muscle fiber type. J Phys Fitness Sports Med 4: 259-270.

Mootha VK, Handschin C, Arlow D, Xie X, St Pierre J, Sihag S, Yang W, Altshuler D, Puigserver P, Patterson N, et al. 2004. Erro and Gabpa/b specify PGC-1 $\alpha$-dependent oxidative phosphorylation gene expression that is altered in diabetic muscle. Proc Natl Acad Sci 101: 6570-6575.

Muoio DM, MacLean PS, Lang DB, Li S, Houmard JA, Way JM, Winegar DA, Corton JC, Dohm GL, Kraus WE. 2002. Fatty acid homeostasis and induction of lipid regulatory genes in skeletal muscles of peroxisome proliferator-activated receptor (PPAR) $\alpha$ knock-out mice. Evidence for compensatory regulation by PPAR $\delta$. J Biol Chem 277: 26089-26097.

Narkar VA, Downes M, Yu RT, Embler E, Wang YX, Banayo E, Mihaylova MM, Nelson MC, Zou Y, Juguilon H, et al.
2008. AMPK and PPAR $\delta$ agonists are exercise mimetics. Cell 134: 405-415.

Narkar VA, Fan W, Downes M, Yu RT, Jonker JW, Alaynick WA, Banayo E, Karunasiri MS, Lorca S, Evans RM. 2011. Exercise and PGC-1 $\alpha$-independent synchronization of type I muscle metabolism and vasculature by ERR $\gamma$. Cell Metab 13: 283-293.

Norris AW, Chen L, Fisher SJ, Szanto I, Ristow M, Jozsi AC, Hirshman MF, Rosen ED, Goodyear LJ, Gonzalez FJ, et al. 2003. Muscle-specific PPAR $\gamma$-deficient mice develop increased adiposity and insulin resistance but respond to thiazolidinediones. J Clin Invest 112: 608-618.

O'Connell MD, Wu FC. 2014. Androgen effects on skeletal muscle: Implications for the development and management of frailty. Asian J Androl 16: 203-212.

Oosthuyse T, Bosch AN. 2012. Oestrogen's regulation of fat metabolism during exercise and gender specific effects. Curr Opin Pharmacol 12: 363-371.

Pardee K, Necakov AS, Krause H. 2011. Nuclear receptors: Small molecule sensors that coordinate growth, metabolism and reproduction. Subcell Biochem 52: 123-153.

Pearen MA, Goode JM, Fitzsimmons RL, Eriksson NA, Thomas GP, Cowin GJ, Wang SC, Tuong ZK, Muscat GE. 2013. Transgenic muscle-specific Nor-1 expression regulates multiple pathways that effect adiposity, metabolism, and endurance. Mol Endocrinol 27: 1897-1917.

Pedersen BK, Saltin B. 2015. Exercise as medicine-Evidence for prescribing exercise as therapy in 26 different chronic diseases. Scand J Med Sci Sports 25: 1-72.

Perez E, Bourguet W, Gronemeyer H, de Lera AR. 2012. Modulation of RXR function through ligand design. Biochim Biophys Acta 1821: 57-69.

Pérez-Schindler J, Summermatter S, Salatino S, Zorzato F, Beer M, Balwierz PJ, van Nimwegen E, Feige JN, Auwerx J, Handschin C. 2012. The corepressor NCoR1 antagonizes PGC- $1 \alpha$ and estrogen-related receptor $\alpha$ in the regulation of skeletal muscle function and oxidative metabolism. Mol Cell Biol 32: 4913-4924.

Pérez-Schindler J, Svensson K, Vargas-Fernandez E, Santos G, Wahli W, Handschin C. 2014. The coactivator PGC-1 $\alpha$ regulates skeletal muscle oxidative metabolism independently of the nuclear receptor PPAR $\beta / \delta$ in sedentary mice fed a regular chow diet. Diabetologia 57: 24052412.

Perry MC, Dufour CR, Tam IS, B'chir W, Giguere V. 2014. Estrogen-related receptor- $\alpha$ coordinates transcriptional programs essential for exercise tolerance and muscle fitness. Mol Endocrinol 28: 2060-2071.

Pojednic RM, Ceglia L. 2014. The emerging biomolecular role of vitamin D in skeletal muscle. Exerc Sport Sci Rev 42: 76-81.

Qaisar R, Bhaskaran S, Van Remmen H. 2016. Muscle fiber type diversification during exercise and regeneration. Free Radic Biol Med 98: 56-67.

Raichur S, Fitzsimmons RL, Myers SA, Pearen MA, Lau P, Eriksson N, Wang SM, Muscat GE. 2010. Identification and validation of the pathways and functions regulated by the orphan nuclear receptor, ROR $\alpha 1$, in skeletal muscle. Nucleic Acids Res 38: 4296-4312.

Ramakrishnan SN, Lau P, Burke LJ, Muscat GE. 2005. Reverb $\beta$ regulates the expression of genes involved in lipid 
absorption in skeletal muscle cells: Evidence for crosstalk between orphan nuclear receptors and myokines. J Biol Chem 280: 8651-8659.

Rangwala SM, Wang X, Calvo JA, Lindsley L, Zhang Y, Deyneko G, Beaulieu V, Gao J, Turner G, Markovits J. 2010 Estrogen-related receptor $\gamma$ is a key regulator of muscle mitochondrial activity and oxidative capacity. J Biol Chem 285: 22619-22629.

Ruas JL, White JP, Rao RR, Kleiner S, Brannan KT, Harrison BC, Greene NP, Wu J, Estall JL, Irving BA, et al. 2012. A PGC- $1 \alpha$ isoform induced by resistance training regulates skeletal muscle hypertrophy. Cell 151: 1319-1331.

Sakai S, Suzuki M, Tashiro Y, Tanaka K, Takeda S, Aizawa K, Hirata M, Yogo K, Endo K. 2015. Vitamin D receptor signaling enhances locomotive ability in mice. $J$ Bone Miner Res 30: 128-136.

Salatino S, Kupr B, Baresic M, van Nimwegen E, Handschin C. 2016. The genomic context and corecruitment of SP1 affect ERR $\alpha$ coactivation by PGC- $1 \alpha$ in muscle cells. Mol Endocrinol 30: 809-825.

Schakman O, Kalista S, Barbe C, Loumaye A, Thissen JP. 2013. Glucocorticoid-induced skeletal muscle atrophy. Int J Biochem Cell Biol 45: 2163-2172.

Schnyder S, Handschin C. 2015. Skeletal muscle as an endocrine organ: PGC-1 $\alpha$, myokines and exercise. Bone $\mathbf{8 0}$ $115-125$.

Schnyder S, Kupr B, Handschin C. 2016. Coregulator-mediated control of skeletal muscle plasticity-A mini-review. Biochimie doi: 10.1016/j.biochi.2016.12.011.

Schuler M, Ali F, Chambon C, Duteil D, Bornert JM, Tardivel A, Desvergne B, Wahli W, Chambon P, Metzger D. 2006. PGC1 $\alpha$ expression is controlled in skeletal muscles by PPAR $\beta$, whose ablation results in fiber-type switching, obesity, and type 2 diabetes. Cell Metab 4: 407-414.

Seth A, Steel JH, Nichol D, Pocock V, Kumaran MK, Fritah A, Mobberley M, Ryder TA, Rowlerson A, Scott J, et al. 2007. The transcriptional corepressor RIP140 regulates oxidative metabolism in skeletal muscle. Cell Metab 6: 236-245.

Smith AG, Muscat GE. 2005. Skeletal muscle and nuclear hormone receptors: Implications for cardiovascular and metabolic disease. Int J Biochem Cell Biol 37: 2047-2063.

Summermatter S, Baum O, Santos G, Hoppeler H, Handschin C. 2010. Peroxisome proliferator-activated receptor $\gamma$ coactivator $1 \alpha$ (PGC-1 $\alpha)$ promotes skeletal muscle lipid refueling in vivo by activating de novo lipogenesis and the pentose phosphate pathway. J Biol Chem 285: 3279332800 .

Svensson K, Albert V, Cardel B, Salatino S, Handschin C. 2016. Skeletal muscle PGC- $1 \alpha$ modulates systemic ketone body homeostasis and ameliorates diabetic hyperketonemia in mice. FASEB J 30: 1976-1986.

Tontonoz P, Cortez-Toledo O, Wroblewski K, Hong C, Lim L, Carranza R, Conneely O, Metzger D, Chao LC. 2015. The orphan nuclear receptor Nur77 is a determinant of myofiber size and muscle mass in mice. Mol Cell Biol 35 : $1125-1138$.

Wall CE, Yu RT, Atkins AR, Downes M, Evans RM. 2016. Nuclear receptors and AMPK: Can exercise mimetics cure diabetes? J Mol Endocrinol 57: R49-R58.

Wang YX, Zhang CL, Yu RT, Cho HK, Nelson MC, BayugaOcampo CR, Ham J, Kang H, Evans RM. 2004. Regulation of muscle fiber type and running endurance by PPARס. PLoS Biol 2: e294.

Wei W, Schwaid AG, Wang X, Wang X, Chen S, Chu Q, Saghatelian A, Wan Y. 2016. Ligand activation of ERRa by cholesterol mediates statin and bisphosphonate effects. Cell Metab 23: 479-491.

Wiik A, Gustafsson T, Esbjornsson M, Johansson O, Ekman M, Sundberg CJ, Jansson E. 2005. Expression of oestrogen receptor $\alpha$ and $\beta$ is higher in skeletal muscle of highly endurance-trained than of moderately active men. Acta Physiol Scand 184: 105-112.

Woldt E, Sebti Y, Solt LA, Duhem C, Lancel S, Eeckhoute J, Hesselink MK, Paquet C, Delhaye S, Shin Y, et al. 2013. Rev-erb- $\alpha$ modulates skeletal muscle oxidative capacity by regulating mitochondrial biogenesis and autophagy. Nat Med 19: 1039-1046.

Yin L, Wu N, Curtin JC, Qatanani M, Szwergold NR, Reid RA, Waitt GM, Parks DJ, Pearce KH, Wisely GB, et al. 2007. Rev-erb $\alpha$, a heme sensor that coordinates metabolic and circadian pathways. Science 318: 1786-1789.

Yu F, Gothe S, Wikstrom L, Forrest D, Vennstrom B, Larsson L. 2000. Effects of thyroid hormone receptor gene disruption on myosin isoform expression in mouse skeletal muscles. Am J Physiol Regul Integr Comp Physiol 278: R1545-R1554. 


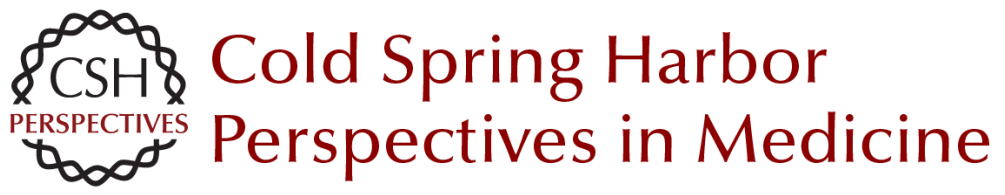

\section{Role of Nuclear Receptors in Exercise-Induced Muscle Adaptations}

Barbara Kupr, Svenia Schnyder and Christoph Handschin

Cold Spring Harb Perspect Med 2017; doi: 10.1101/cshperspect.a029835 originally published online February 27, 2017

\section{Subject Collection The Biology of Exercise}

Exosomes as Mediators of the Systemic

Adaptations to Endurance Exercise Adeel Safdar and Mark A. Tarnopolsky

Molecular Basis of Exercise-Induced Skeletal

Muscle Mitochondrial Biogenesis: Historical

Advances, Current Knowledge, and Future

Challenges

Christopher G. R. Perry and John A. Hawley

Exercise Metabolism: Fuels for the Fire Mark Hargreaves and Lawrence L. Spriet

Health Benefits of Exercise Gregory N. Ruegsegger and Frank W. Booth

Molecular Regulation of Exercise-Induced Muscle

Fiber Hypertrophy Marcas M. Bamman, Brandon M. Roberts and Gregory R. Adams

Physiological Redundancy and the Integrative Responses to Exercise Michael J. Joyner and Jerome A. Dempsey

On the Run for Hippocampal Plasticity C'iana Cooper, Hyo Youl Moon and Henriette van Praag

Molecular Basis for Exercise-Induced Fatigue: The Importance of Strictly Controlled Cellular $\mathrm{Ca}$

2+ Handling

Arthur J. Cheng, Nicolas Place and Håkan

Westerblad
Effects of Exercise and Aging on Skeletal Muscle Giovanna Distefano and Bret $H$. Goodpaster

Muscle-Adipose Tissue Cross Talk Kristin I. Stanford and Laurie J. Goodyear

Performance Fatigability: Mechanisms and Task Specificity

Sandra K. Hunter

Adaptations to Endurance and Strength Training David C. Hughes, Stian Ellefsen and Keith Baar

The Bioenergetics of Exercise

$P$. Darrell Neufer

Effects of Exercise on Vascular Function,

Structure, and Health in Humans

Daniel J. Green and Kurt J. Smith

Control of Muscle Metabolism by the Mediator

Complex

Leonela Amoasii, Eric N. Olson and Rhonda

Bassel-Duby

Theoretical and Biological Evaluation of the Link between Low Exercise Capacity and Disease Risk Lauren Gerard Koch and Steven L. Britton

For additional articles in this collection, see http://perspectivesinmedicine.cshlp.org/cgi/collection/ 